\title{
Membrane-Bound Alcohol Dehydrogenase Is Essential for Glyceric Acid Production in Acetobacter tropicalis
}

\author{
Hiroshi Habe ${ }^{1 *}$, Shun Sato ${ }^{1}$, Tokuma Fukuoka1, Dai Kitamoto ${ }^{1}$, Toshiharu Yakushi ${ }^{2}$, \\ Kazunobu Matsushita ${ }^{2}$, and Keiji Sakaki ${ }^{1}$ \\ ${ }^{1}$ Research Institute for Innovation in Sustainable Chemistry, National Institute of Advanced Industrial Science and Technology (AIST) (5-2 \\ Central, 1-1-1 Higashi, Tsukuba, Ibaraki 305-8565, JAPAN) \\ ${ }^{2}$ Department of Biological Chemistry, Faculty of Agriculture, Yamaguchi University (1677-1 Yoshida, Yamaguchi, Yamaguchi 753-8515, JAPAN)
}

\begin{abstract}
Acetobacter tropicalis NBRC16470 can produce highly enantiomerically pure D-glyceric acid (D-GA; >99\% enantiomeric excess) from glycerol. To investigate whether membrane-bound alcohol dehydrogenase (mADH) is involved in GA production in $A$. tropicalis, we amplified part of the gene encoding mADH subunit I ( $a d h A)$ using polymerase chain reaction and constructed an adh $A$-disrupted mutant of $A$. tropicalis $(\triangle a d h A)$. Because $\triangle a d h A$ did not produce GA, we confirmed that $\mathrm{mADH}$ is essential for the conversion of glycerol to GA. We also cloned and sequenced the entire region corresponding to $a d h A$ and $a d h B$, which encodes $m A D H$ subunit II. The sequences showed high identities (84-86 \%) with the equivalent mADH subunits from other Acetobacter spp.
\end{abstract}

Key words: glycerol use, glyceric acid, alcohol dehydrogenase, Acetobacter tropicalis, acetic acid bacteria

\section{INTRODUCTION}

Glycerol is a renewable feedstock derived largely from natural sources such as vegetable oils and animal fats. It is produced as a by-product in biodiesel fuel(BDF) production and the oleochemical industry. As glycerol production expands owing to increased use of BDF, the price of glycerol is expected to drop. The efficient use of glycerol may be a key factor in both BDF and oleochemical manufacturing processes.

The production of glyceric acid (GA) from glycerol using biotechnological processes has been investigated as a potential use of glycerol ${ }^{1-7)}$. GA has reported biological functions as a liver stimulant and cholesterolytic agent in $\operatorname{logs}^{8)}$ and an inducer of ethanol and acetaldehyde oxidation in rats $^{9}$. These properties suggest that GA is a promising chemical, but it is expensive as a reagent for investigational use. Hence, the development of a cheaper GA manufacturing process is important.

Previously, we investigated the biotechnological production of GA using acetic acid bacteria $(\mathrm{AAB})$ and examined the abilities of $162 \mathrm{AAB}$ strains to produce GA from glycerol. We found that the patterns of productivity and enantiomeric GA composition among the $\mathrm{AAB}$ strains differed sig- nificantly ${ }^{4)}$. For example, under optimal cultivation conditions in a jar fermentor, Gluconobacter frateurii accumulated $136.5 \mathrm{~g} / \mathrm{L}$ of GA with a 72\% D-GA enantiomeric excess (ee), whereas Acetobacter tropicalis produced $101.8 \mathrm{~g} / \mathrm{L}$ D-GA with a $99 \%$ ee. To the best of our knowledge, A. tropicalis NBRC16470 is the only species that can produce highly enantiomerically pure D-GA $(>99 \% \text { ee })^{1,4)}$.

At the same time, gene disruption analysis using Gluconobacter oxydans revealed that the membrane-bound alcohol dehydrogenase (mADH) -encoding gene $a d h A$ is required for GA production; moreover, purified $\mathrm{mADH}$ from G. oxydans catalyzed the oxidation of glycerol to glyceraldehyde $^{4)}$. These results suggest that mADHs are also involved in GA production in G. frateurii and A. tropicalis. No direct evidence shows that $\mathrm{mADH}$ is essential for GA production in A. tropicalis, however. Additionally, studies of mADH from Acetobacter spp., Gluconobacter spp., and Gluconacetobacter spp. have shown that mADH usually consists of three subunits (I, II, and III; for an excellent recent review, see Yakushi and Matsushita, 2010) ${ }^{10)}$; however, no sequences of the respective $\mathrm{mADH}$ components from A. tropicalis have been available to date.

Subunit I contains pyrroloquinoline quinone (PQQ) and

\footnotetext{
*Correspondence to: Hiroshi Habe, Research Institute for Innovation in Sustainable Chemistry, National Institute of Advanced Industrial Science and Technology (AIST), 5-2 Central, 1-1-1 Higashi, Tsukuba, Ibaraki 305-8565, JAPAN

E-mail: hiroshi.habe@aist.go.jp

Accepted May 14, 2011 (received for review April 10, 2011)

Journal of Oleo Science ISSN 1345-8957 print / ISSN 1347-3352 online

http://www.jstage.jst.go.jp/browse/jos/ http://mc.manusriptcentral.com/jjocs
} 


\section{H. Habe, S. Sato, T. Fukuoka et al.}

one heme $c$ moiety as a prosthetic group, and functions as the actual catalytic site for glycerol oxidation as well as ethanol oxidation, whereas subunit II works as the electron mediator from subunit I, and subunit III seems to be a molecular chaperone for the folding of subunit $\mathrm{I}^{10)}$. Among these $\mathrm{mADH}$ subunits, the sequence of subunit I is the most important for us to know as a first step in understanding how A. tropicalis produces enantiomerically pure D-GA.

In this study, we first investigated the involvement of $\mathrm{mADH}$ in GA production in A. tropicalis (Fig. 1). We then cloned and sequenced the DNA region containing the two genes encoding $\mathrm{mADH}$ subunits.

\section{EXPERIMENTAL PROCEDURES}

\subsection{Materials}

All reagents and solvents were commercially available and of the highest purity (Sigma-Aldrich, St. Louis, MO; Kanto Chemical, Tokyo, Japan; Wako Pure Chemical, Osaka, Japan; Nacalai Tesque, Kyoto, Japan).

\subsection{Apparatus}

The concentration of D-GA in culture broth was analyzed using high-performance liquid chromatography (HPLC) with an LC-20AD HPLC pump (1.0 mL/min flow rate) and an RID-10A detector (Shimadzu) equipped with a Shodex ${ }^{\circledR}$ SH1011 column (Showa Denko) for GA. Mobile phases of 5 $\mathrm{mM} \mathrm{H}_{2} \mathrm{SO}_{4}$ was used for the column. During the analysis, the columns were maintained at $60^{\circ} \mathrm{C}$.

\subsection{Bacterial strains}

A. tropicalis NBRC16470 was originally obtained from the National Institute of Technology and Evaluation (NITE), Japan ${ }^{1,4)}$. Stock cultures were routinely cultivated at $30^{\circ} \mathrm{C}$ on agar medium containing $5 \mathrm{~g} / \mathrm{L}$ polypeptone (Nihon Pharmaceutical, Tokyo, Japan), 5 g/L yeast extract (Difco Laboratories, Detroit, MI), 5 g/L glucose, and $1 \mathrm{~g} / \mathrm{L}$ $\mathrm{MgSO}_{4} \cdot 7 \mathrm{H}_{2} \mathrm{O}(\mathrm{pH}$ 6.5). When necessary, kanamycin (Km) was added to the media at a final concentration of $50 \mu \mathrm{g} /$ $\mathrm{mL}$. Escherichia coli strain JM109 ${ }^{11)}$ was cultivated at $37^{\circ} \mathrm{C}$ using Luria-Bertani broth, $2 \times \mathrm{YT}$ medium, or Terrific broth, as described by Sambrook and Russell (2001). Ampicillin and $\mathrm{Km}$ were added to the media when necessary at



Fig. 1 Pathways for the conversion of glycerol to D-glyceric acid by Acetobacter tropicalis. final concentrations of $50 \mu \mathrm{g} / \mathrm{mL}$.

\subsection{DNA manipulations}

Total DNA extraction, plasmid isolation, restriction endonuclease digestion, cloning, and the transformation of $E$. coli were carried out using standard protocols ${ }^{11)}$.

\subsection{PCR amplification of partial adhA}

To amplify the DNA region within $a d h A$ using polymerase chain reaction (PCR), we used a primer set (AtADH-F1, 5' -GCTGACAAAGGCTGCTGTGA-3' , and AtADH-R1, 5' -AGGCTTCATGCTGGTGTCGA-3' ) designed according to information from the draft genomic sequence of A. tropicalis SKU1100 (NBRC 101654; Matsutani et al., submitted for publication; the data will be available under GenBank accession nos. BABS01000001-BABS01000773). After an initial denaturation at $94^{\circ} \mathrm{C}$ for $2 \mathrm{~min}$, three cycles at $94^{\circ} \mathrm{C}$ for $1 \mathrm{~min}$, at $65^{\circ} \mathrm{C}$ for $1 \mathrm{~min}$, and at $72^{\circ} \mathrm{C}$ for $2 \mathrm{~min}$ were run with the above primers. The program ended with a 10 -min extension at $72^{\circ} \mathrm{C}$. The product (approximately $1.5 \mathrm{~kb}$ ) was purified using agarose gel electrophoresis, cloned into pT7Blue (R) (Novagen, Madison, WI), and sequenced (designated pT7-adhA).

\subsection{Disruption of adhA and GA productivity of $\Delta a d h A$}

The DNA region containing the $\mathrm{Km}^{\mathrm{r}}$ cassette $(\sim 0.9 \mathrm{~kb})$ from pTKm ${ }^{12)}$ was excised via EcoRV digestion and ligated to the HpaI site in the partial adhA gene of pT7-adhA. The resultant plasmid, pT7-AtADH::Km, was introduced into $A$. tropicalis NBRC16470 with electroporation (electroporator settings: $200 \Omega, 25 \mu \mathrm{F}$, and $1.9 \mathrm{kV}$ ). Next, the $a d h A$ disruptant, $\Delta a d h \mathrm{~A}$, was screened on YPG ( $5 \mathrm{~g} / \mathrm{L}$ yeast extract, 2 $\mathrm{g} / \mathrm{L}$ peptone, and $30 \mathrm{~g} / \mathrm{L}$ glucose) plates ${ }^{13)}$ containing $\mathrm{Km}$.

Wild-type A. tropicalis and its $\triangle a d h A$ mutant were precultivated in $5 \mathrm{~mL}$ of media consisting of $5 \mathrm{~g} / \mathrm{L}$ glucose, 20 $\mathrm{g} / \mathrm{L}$ glycerol, $10 \mathrm{~g} / \mathrm{L}$ yeast extract, $10 \mathrm{~g} / \mathrm{L}$ polypeptone, and $4 \mathrm{~g} / \mathrm{L}$ potato extract(Difco Laboratories) at $30^{\circ} \mathrm{C}$ for 1 day, after which the seed cultures $(1.5 \mathrm{~mL})$ were transferred to 300-mL Erlenmeyer flasks containing $30 \mathrm{~mL}$ of media consisting of $150 \mathrm{~g} / \mathrm{L}$ glycerol, $0.9 \mathrm{~g} / \mathrm{L} \mathrm{KH}_{2} \mathrm{PO}_{4}, 0.1 \mathrm{~g} / \mathrm{L} \mathrm{K}_{2} \mathrm{HPO}_{4}$, $20 \mathrm{~g} / \mathrm{L}$ yeast extract, and $1 \mathrm{~g} / \mathrm{L} \mathrm{MgSO}_{4} \cdot 7 \mathrm{H}_{2} \mathrm{O}(\mathrm{pH}$ 6.5). The flasks were incubated for 4 days at $30^{\circ} \mathrm{C}$ on a rotary shaker (200 rpm). After removal of the cells with centrifugation, the respective supernatants were analyzed using HPLC.

\subsection{Genomic library screening and sequence analysis}

A genomic fosmid library of A. tropicalis was constructed as described previously ${ }^{14)}$. To screen for positive clones carrying the amplified DNA fragment described above, colony PCR experiments were carried out using 96-well deep-well plates and the primers AtADH-F1 and AtADH-R1. One of the positive fosmid clones, pCC1FOSAT1, was used in our subsequent analyses. Sequencing of pCC1FOSAT1 was performed at the Takara Dragon Ge- 
nomics Center(Mie, Japan). To identify open reading frames (ORFs), the nucleotide sequence was analyzed with Genetix software(version 8.0; Genetix, New Milton, UK). Homology searches were carried out using the SWISSPROT protein sequence database or DNA DataBank of Japan(DDBJ), European Molecular Biology Laboratory (EMBL), and GenBank nucleotide sequence databases with the BLAST program ${ }^{15)}$. All automated ORF predictions and functional assignments were controlled manually for the entire contiguous DNA sequence.

\subsection{Nucleotide sequence accession number}

The nucleotide sequence of the 9.9-kb DNA region in the pCC1FOSAT1 insert was deposited in the DDBJ, EMBL, and GenBank nucleotide sequence databases under accession no. AB623210.

\section{RESULTS AND DISCUSSION}

\subsection{PCR amplification of the internal DNA region of adhA from A. tropicalis NBRC16470}

As a preliminary step toward analyzing the sequences of mADH genes from $A$. tropicalis NBRC16470, we attempted to amplify the internal region of adhA with PCR using the primer set described above. The amplified DNA fragment was cloned into pT7Blue (R) to construct pT7-adhA and then sequenced. The partial $a d h A$ homolog from $A$. tropicalis NBRC16470 was similar to the $a d h A$ sequences from Acetobacter pasteurianus ${ }^{16)}$ and Acetobacter aceti ${ }^{17)}$; the sequence of the translated polypeptide was $86 \%$ identical to AdhA from $A$. pasteurianus and $85 \%$ identical to that from A. aceti. Usually, AdhA contains PQQ and one heme $c$, and the amino acid residues involved in both PQQ and heme $c$ binding have been identified in $\mathrm{ADH}$ based on genetic and structural information ${ }^{18)}$. Within the sequenced region of the AdhA homolog, amino acid residues involved in PQQ binding were also identified (alignment not shown).

\subsection{Involvement of mADH in GA production}

To investigate the involvement of $a d h A$ in GA production, the $a d h A$ homolog was disrupted via homologous recombination. For this purpose, pT7-AtADH::Km was first constructed using both pT7-adhA and the $\mathrm{Km}^{\mathrm{r}}$ cassette from $\mathrm{pTKm}^{12)}$ and was subsequently introduced into $A$. tropicalis NBRC16470 to isolate the recombinant. The re-

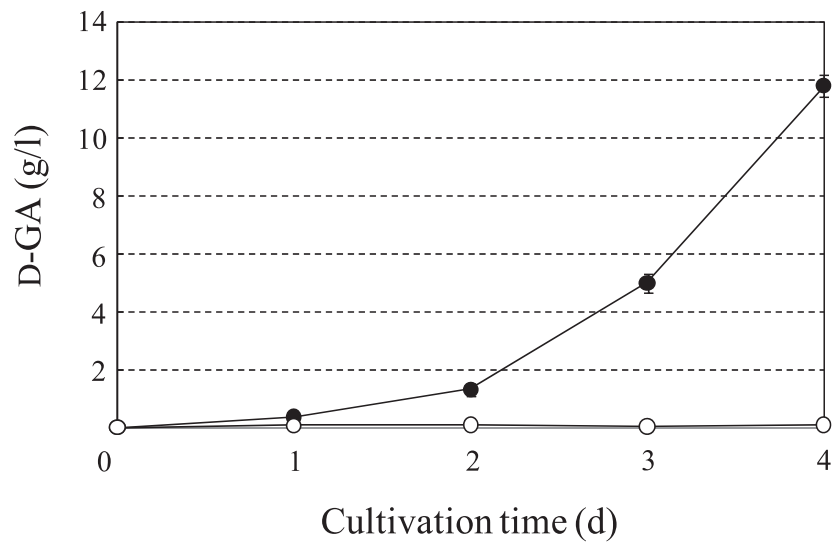

Fig. 2 Time course of D-glyceric acid production from glycerol by Acetobacter tropicalis NBRC16470 and $\triangle a d h A$. Black circles, wild-type $A$. tropicalis NBRC16470; white circles, $\triangle a d h A$.

sultant mutant, $\triangle a d h A$, was examined for its GA productivity. As shown in Fig. 2, the wild-type strain produced 11.8 g/L GA, whereas $\triangle a d h A$ produced only $0.09 \mathrm{~g} / \mathrm{L}$ GA after a 4-day incubation. This indicates that the $\operatorname{adhA}$ homolog is a component of $\mathrm{mADH}$ and that $\mathrm{mADH}$ is involved in GA production in A. tropicalis NBRC16470.

\subsection{Isolation of fosmid clones carrying adhA}

A fosmid library of genomic DNA from A. tropicalis was constructed. In the initial screen for positive clones, 576 of the resultant fosmid clones were screened with colony PCR using 96-well deep-well plates (six clones per well), and in nine wells, the amplification of an approximately $1.5-\mathrm{kb}$ DNA fragment was observed. Next, using the 54 clones from the nine wells, a second round of screening was performed. Amplification of the expected DNA fragment was observed in three clones. One of them, pCC1FOSAT1, was selected for further sequence analysis.

\subsection{Nucleotide sequence analysis and identification of the genes encoding $\mathrm{mADH}$ subunits}

Sequencing of part of the fosmid clone gave a 9.9-kb contiguous sequence. In this region, we found six ORFs, and among them, ORF5 and ORF6 were homologous to $\operatorname{adh} A$ (mADH subunit I) and $a d h B$ (mADH subunit II), respectively (Fig. 3; Table 1). Upstream of the $a d h A B$ genes, we identified ORFs homologous to the genes encoding cytochrome $o$ ubiquinol oxidase subunits I, II, and III (Fig. 3;

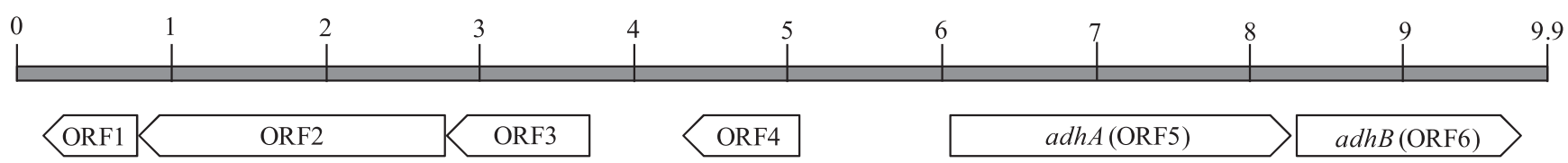

Fig. 3 Diagram indicating the positions of open reading frames present in the fosmid insert $(9.9 \mathrm{~kb})$. Blocks indicate the size, location, and direction of transcription of the genes. 
Table 1 Annotated open reading frames (ORFs) of the DNA region analyzed $(9.9 \mathrm{~kb})$.

\begin{tabular}{|c|c|c|c|c|c|c|}
\hline \multicolumn{3}{|c|}{ ORF } & \multicolumn{4}{|c|}{ Homologous protein } \\
\hline Name & Length (aa) & Probable Function & Protein & Source & Identity (aa \%) & Accession No. \\
\hline ORF1* & 201 & $\begin{array}{l}\text { Cytochrome } o \text { ubiquinol } \\
\text { oxidase, subunit III }\end{array}$ & $\begin{array}{l}\text { Cytochrome } o \text { ubiquinol } \\
\text { oxidase, subunit III }\end{array}$ & $\begin{array}{l}\text { Acetobacter pomorum } \\
\text { DM001 }\end{array}$ & 92 & EGE47621 \\
\hline ORF2* & 663 & $\begin{array}{l}\text { Cytochrome } o \text { ubiquinol } \\
\text { oxidase, subunit I }\end{array}$ & $\begin{array}{l}\text { Cytochrome } o \text { ubiquinol } \\
\text { oxidase subunit I }\end{array}$ & $\begin{array}{l}\text { Acetobacter pasteurianus } \\
\text { IFO3283-01 }\end{array}$ & 93 & YP_003186627 \\
\hline ORF3* & 307 & $\begin{array}{l}\text { Cytochrome } o \text { ubiquinol } \\
\text { oxidase, subunit II }\end{array}$ & $\begin{array}{l}\text { Cytochrome } o \text { ubiquinol } \\
\text { oxidase subunit II }\end{array}$ & $\begin{array}{l}\text { Acetobacter pasteurianus } \\
\text { IFO3283-01 }\end{array}$ & 94 & YP_003186627 \\
\hline ORF4* & 258 & Unknown & Hypothetical protein & $\begin{array}{l}\text { Acetobacter pomorum } \\
\text { DM001 }\end{array}$ & 79 & EGE47618 \\
\hline ORF5 & 742 & $\begin{array}{l}\text { Membrane-bound alcohol } \\
\text { dehydrogenase, subunit I }\end{array}$ & AdhA & $\begin{array}{l}\text { Acetobacter pasteurianus } \\
\text { IFO3283-01 }\end{array}$ & 86 & YP_003186627 \\
\hline ORF6 & 144 & $\begin{array}{l}\text { Membrane-bound alcohol } \\
\text { dehydrogenase, subunit II }\end{array}$ & AdhB & $\begin{array}{l}\text { Acetobacter pasteurianus } \\
\text { IFO3283-01 }\end{array}$ & 85 & YP_003186627 \\
\hline
\end{tabular}

*ORFs are encoded in the complementary strand.

(a)

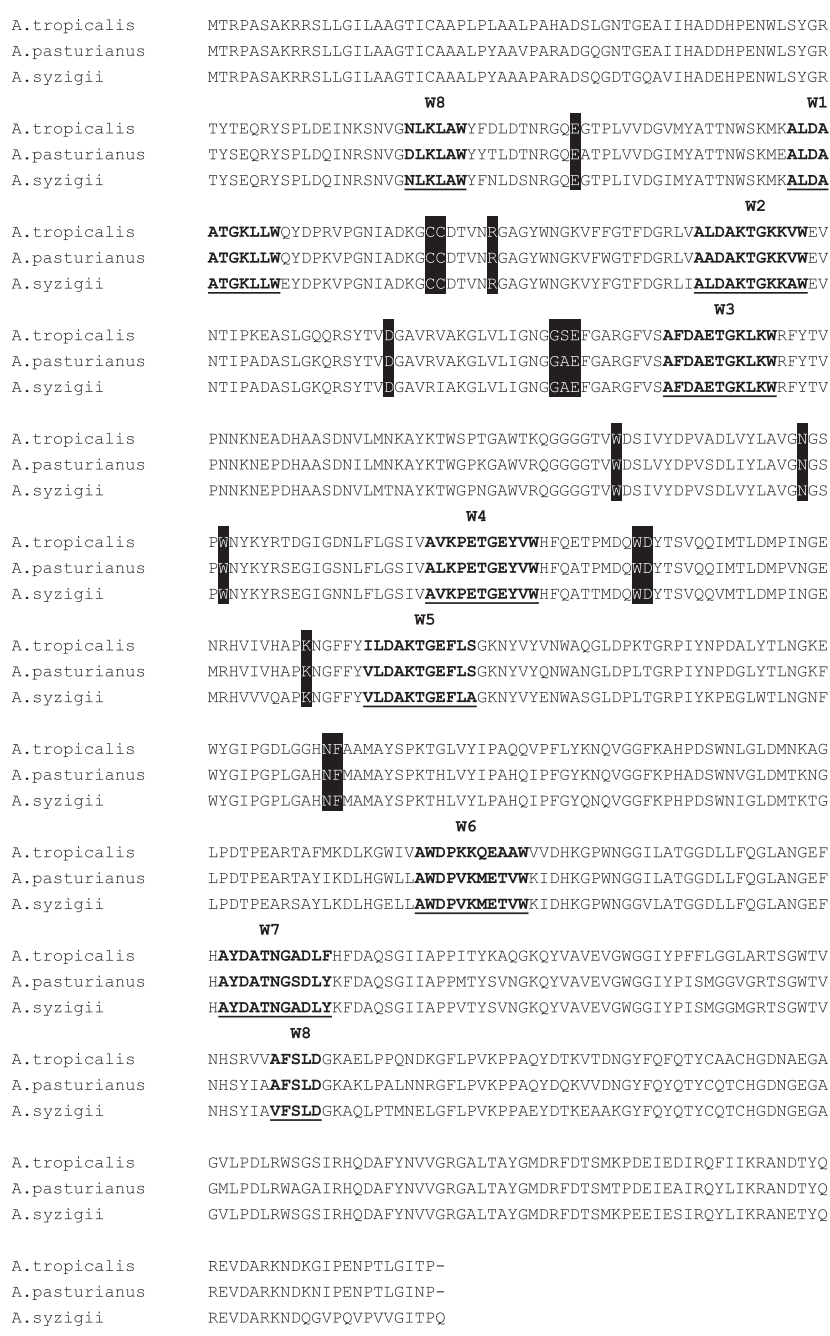

(b)

A.tropicalis -MIKGLKAALGAVAVGLLAGTSLAHAQSADDELVKKGAYVARLGDCVACHTALHGQVYAG A.pasturianus MMINRLKAALGAVAVGLLAGTSLAHAQNADEDLIKKGEYVARLGDCVACHTSLNGQKYAG A.syzigii MMMNRLKAALGAVTVGLLAGTSLAHAQGADEDLIKKGEYVARLGDCVACHTALNGQKFAG

A.tropicalis A.pasturianus GLSIKTPIGTIYSTNITPDPTYGIGTYTFKEFDEAVRHGVRKDGATLYPAMPYPSFARMT A.syzigii GLAIKTPIGMIYSTNITPDPTYGIGTYTLQEFDEAVRHGVRKDGSTLYPAMPYPSFARMS

A.tropicalis A. pasturianus A.syzigii

A.tropicalis A.pasturianus A.syzigii

A.tropicalis A. pasturianus A.syzigii

A.tropicalis A.pasturianus A.syzigii

A.tropicalis A.pasturianus A.syzigii

A.tropicalis A.pasturianus A.syzigii
GLAIKTP I GMIYSTNI TPDPTYGIGTYTLQEFDEAVRHGVRKDGSTLYPAMPYPSEARMS QDDMKALYYYFMHGVQPIAQKNHPTDI SWPMSMRWPLS IWRSVFAPAPKDFTPAPGTDAE QDDIKSLYAYFMHGVKPIAQKNRETGISWPLSMRWPLS IWRSMEAPT PKDETPAPGTDAD

IARGEYLVTGPGHCGACHTPRGFGMQEKALDASGGADFLSGGAPIDNWIAPSLRNDPVLG IARGEYLVTGPGHCGACHTPRGFGMOEKALDASGGPDFLGGGGVIDNWIAPSIRNDPULG IARGEYLVTGAGHCGACHTPRGFAMOEKALDASGGPDFLAGGAPIDNWIAPSLRNDPVVG

LGRWSEDDIYQFLKSGRIDHSAVFGGMADVVGWSTQYFTDSDLRAMAKYLKALPPVPPAR LGRWSDEDLFLFLKSGRTDHSAAFGGMADVVGWSTQYFTDADLHAMVKYIKSLPPVPPAR LGRWSEDDIYLFLKSGRTDHSAVFGGMADVVGWSTQYFTDSDLHAIAKYLKSMPPVPPSR

GDYKYDASTAQALDSHNTSGMPGAKEYVEQCAICHRNDGGGVARMFPPLAGNPVVVSENP GDYSYDASTAQMLDSNNESGNAGAKTYVEQCAICHRNDGGGVARMFPPLAGNPVVVSDNP GDYTYDPSTAQALDSGNTANNPGARVYVEQCAACHRNDGGGVARMFPPLAGNPVVVGDDP

TSVAHT TVAGAVLIPPTNWAPSAVAMPGYKNVL,SDQQTADVVNFTRTSWGNKA PANVTAAD TSVAHIVVDGGVLPPTNWAPSAVAMPDYKNI LSDQQIADVVNFIRSAWGNRAPANTTAAD TSIAHIVMAGGVLPPTNWAPSAVAMPDYKNILSDQQMADVVNE IRSAWGNKAPANVTAAD

IQKLRVDHAPISTYSWGEGGNDTATWGVFHPQPYGAGWTFAPQTHTGEDEAQ IQKLRLDHTPLPTPGWANATEESATWGLFMPQPYGAGWTFAPQTHAGVDEAQ VQKLRLDHAPIPTTGWADPTSATSTWGLFMPQPYGSGWTFAPQTHTGVDEAQ

Fig. 4 Alignment of the amino acid sequences of the respective membrane-bound alcohol dehydrogenase subunits. (a) Subunit I (AdhA), (b) subunit II (AdhB). W-motifs (W1-W8) are underlined with bold letters. Amino acid residues involved in pyrroloquinoline quinone (PQQ)-binding and heme $C$ binding are indicated by highlighted letters and shaded in grey, respectively. 
see Table 1)

(i) AdhA. The nucleotide sequence of $a d h A$ is 2,229 bp, and the deduced amino acid sequences of $a d h A$ shared the highest identity with AdhA from A. pasteurianus IFO3283-01 $(86 \%)^{16)}$, A. $\operatorname{aceti}(86 \%)^{17)}$, and A. syzygii (84\%; accession no. BAE97418). In the AdhA sequence from $A$. tropicalis, amino acid residues involved in PQQ and heme $c$ binding were highly conserved (Fig. 4a).

PQQ-containing quinoproteins have a common basic structure called a propeller fold superbarrel made up of eight four-stranded anti-parallel $\beta$-sheets called W motifs because they look like the letter $\mathrm{W}^{18,19)}$. In the AdhA sequence, W-motifs (W1-W8) were also conserved (see Fig. 4a).

(ii) AdhB. The nucleotide sequence of $a d h B$ is $1,416 \mathrm{bp}$, and the deduced amino acid sequences of $a d h B$ shared the highest homology with AdhB from A. pasteurianus IFO3283-01 (85\% $)^{16)}$, Acetobacter pomorum DM001 (85\%; EGE47615), and Acetobacter syzygii (84\%; accession no. BAE97419). In the AdhB sequence from A. tropicalis, amino acid residues involved in heme $c$ binding (three regions) were conserved (Fig. 4b).

The results of our sequence comparison of mADH subunit-encoding genes suggest that these two genes, which are highly homologous to $a d h A$ and $a d h B$ from Acetobacter spp., are functional in A. tropicalis NBRC16470. The strong homologies among $A$. tropicalis, A. pasteurianus, and A. syzygii suggest that $\mathrm{mADH}$ is also involved in GA production in A. pasteurianus and A. syzygii.

\section{CONCLUSIONS}

This study showed that mADH is essential for GA production in A. tropicalis NBRC14670, which produces enantiomerically pure D-GA, because the disruption of $a d h A$, which encodes a dehydrogenase subunit (subunit I) of $\mathrm{mADH}$, eliminated GA production. We also isolated and sequenced the genes encoding the subunits of $\mathrm{mADH}(a d h A$ and $a d h B)$. The strong sequence similarities to the corresponding $\mathrm{mADH}$ components from other Acetobacter spp. suggest that these subunits are functional in A. tropicalis NBRC16470. To understand the detailed mechanism of enantiomerically pure D-GA production by mADH, purification and crystallization of the enzyme complex, including subunit III, to determine the three-dimensional structure will be necessary.

\section{ACKNOWLEDGEMENTS}

This work was supported financially in part by the JapanUS Cooperation Project for Research and Standardization of Clean Energy Technologies from the Ministry of
Economy, Trade and Industry of Japan.

\section{References}

1) Habe, H.; Fukuoka, T.; Kitamoto, D.; Sakaki, K. Biotransformation of glycerol to D-glyceric acid by Acetobacter tropicalis. Appl. Microbiol. Biotechnol. 81, 1033-1039 (2009).

2) Habe, H.; Fukuoka, T.; Kitamoto, D.; Sakaki, K. Application of electrodialysis to glycerate recovery from a glycerol containing model solution and culture broth. J. Biosci. Bioeng. 107, 425-428(2009).

3) Habe, H.; Shimada, Y.; Fukuoka, T.; Kitamoto, D.; Itagaki, M.; Watanabe, K.; Yanagishita, H.; Sakaki, K. Production of glyceric acid by Gluconobacter sp. NBRC3259 using raw glycerol. Biosci. Biotechnol. Biochem. 73, 1799-1805(2009).

4) Habe, H.; Shimada, Y.; Yakushi, T.; Hattori, H.; Ano, Y.; Fukuoka, T.; Kitamoto, D.; Itagaki, M.; Watanabe, K.; Yanagishita, H.; Matsushita, K.; Sakaki, K. Microbial production of glyceric acid, an organic acid that can be mass produced from glycerol. Appl. Environ. Microbiol. 75, 7760-7766(2009).

5) Habe, H.; Fukuoka, T.; Morita, T.; Kitamoto, D.; Yakushi, T.; Matsushita, K.; Sakaki, K. Disruption of the membrane-bound alcohol dehydrogenase-encoding gene improved glycerol use and dihydroxyacetone productivity in Gluconobacter oxydans. Biosci. Biotechnol. Biochem. 74, 1391-1395(2010).

6) Habe, H.; Shimada, Y.; Fukuoka, T.; Kitamoto, D.; Itagaki, M.; Watanabe, K.; Yanagishita, H.; Sakaki, K. Use of a Gluconobacter frateurii mutant to prevent dihydroxyacetone accumulation during glyceric acid production from glycerol. Biosci. Biotechnol. Biochem. 74, 2330-2332 (2010).

7) Habe, H.; Shimada, Y.; Fukuoka, T.; Kitamoto, D.; Itagaki, M.; Watanabe, K.; Yanagishita, H.; Sakaki, K. Two-stage electrodialytic concentration of glyceric acid from fermentation broth. J. Biosci. Bioeng. 110, 690-695 (2010).

8) Handa, S. S.; Sharma, A.; Chakraborti, K. K. Natural products and plants as liver protecting drugs. Fitoterapia 57, 307-351 (1986).

9) Eriksson, C. J. P.; Saarenmaa, T. P. S.; Bykov, I. L.; Heino, P. U. Acceleration of ethanol and acetaldehyde oxidation by D-glycerate in rats. Metabolism 56, 895-898 (2007).

10) Yakushi, T.; Matsushita, K. Alcohol dehydrogenase of acetic acid bacteria: structure, mode of action, and applications in biotechnology. Appl. Microbiol. Biotechnol. 86, 1257-1265 (2010).

11) Sambrook, J.; Russell, D. W. Molecular Cloning, a Laboratory Manual. $3^{\text {rd }}$ ed. Cold Spring Harbor Labo- 


\section{H. Habe, S. Sato, T. Fukuoka et al.}

ratory. Cold Spring Harbor (2001).

12) Yoshida, T.; Ayabe, Y.; Yasunaga, M.; Usami, Y.; Habe, H.; Nojiri, H.; Omori, T. Genes involved in the synthesis of the exopolysaccharide methanolan by the obligate methylotroph Methylobacillus sp. Strain 12S. Microbiol. 149, 431-444 (2003).

13) Tonouchi, N.; Sugiyama, M.; Yokozeki, K. Construction of a vector plasmid for use in Gluconobacter oxydans. Biosci. Biotechnol. Biochem. 67, 211-213 (2003).

14) Habe, H.; Kobuna, A.; Hosoda, A.; Kouzuma, A.; Yamane, H.; Nojiri, H.; Omori, T.; Watanabe, K. Appl. Microbiol. Biotechnol. 79, 87-95(2008).

15) Altschul, S. F.; Madden, T. L.; Schaffer, A. A.; Zhang, J.; Zhang, Z.; Miller, W.; Lipman, D. J. Nucleic Acids Res. 25, 3389-3420 (1997).

16) Azuma, Y.; Hosoyama, A.; Matsutani, M.; Furuya, N.; Horikawa, H.; Harada, T.; Hirakawa, H.; Kuhara, S.;
Matsushita, K.; Fujita, N.; Shirai, M. Whole-genome analyses reveal genetic instability of Acetobacter pasteurianus. Nucleic Acids Res. 37, 5768-5783 (2009).

17) Inoue, T.; Sunagawa, M.; Mori, A.; Imai, C.; Fukuda, M.; Takagi, M.; Yano, K. Cloning and sequencing of the gene encoding the 72-kilodalton dehydrogenase subunit of alcohol dehydrogenase from Acetobacter aceti. J. Bacteriol. 171, 3115-3122 (1989).

18) Toyama, H.; Mathews, F. S.; Adachi, O.; Kazunobu, M. Quinohemoprotein alcohol dehydrogenase: structure, function, and physiology. Arch. Biochem. Biophys. 428, 10-21 (2004).

19) Kanchanarach, W.; Theeragool, G.; Yakushi, T.; Toyama, H; Adachi, O.; Matsushita, K. Characterization of thermotolerant Acetobacter pasteurianus strains and their quinoprotein alcohol dehydrogenases. Appl. Microbiol. Biotechnol. 85, 741-751(2010). 